\title{
Taxonomic Distribution of the Antigen Eliciting Bactericidal Antibody for Bordetella pertussis
}

\author{
By JEAN M. DOLBY* AND J. P. ACKERS $\uparrow$ \\ The Lister Institute of Preventive Medicine, Elstree, Hertfordshire
}

(Received I May 1974; revised I November 1974)

\begin{abstract}
SUMMARY
Strains of Bordetella pertussis varied in their ability to elicit (in mice) an antibody bactericidal for an antiserum-sensitive strain of $B$. pertussis, although antibody was usually detectable after only one injection. High titres were produced by a course of seven injections with all strains of $B$. pertussis tested (six of phase I and three of phase IV) but not with three strains of other Bordetella species nor with two unrelated organisms, a finding of possible taxonomic value.

Preliminary investigations have not revealed whether strain variations are due to quantitative or qualitative differences in either the bacterial lipopolysaccharide or the carrier protein necessary for antibody production, or whether they may be due to differences in heat lability of 'bactericidal antigen'.
\end{abstract}

\section{INTRODUCTION}

Lipopolysaccharide (LPS) of Bordetella pertussis elicits bactericidal antibody active in vitro in the presence of complement against serum-sensitive strains (Pusztai, Csizer \& Joo, I97I $b$; Ackers \& Dolby, I972). The antigen called here the 'bactericidal antigen' is of interest because it is still present in several artificially-produced variants of $B$. pertussis and is not one of the many antigens lost on the conversion of phase I organisms to the nutritionally less exacting and antigenically different phase IV (Ackers \& Dolby, 1972). It seemed that the ability to stimulate bactericidal antibody might at times be of help in identifying nutritionally non-exacting, non-fermenting Gram-negative organisms and other derivatives.

Bactericidal antibody was not elicited to the same extent by all strains. We had previously shown (Ackers \& Dolby, 1972) that some strains of Bordetella pertussis, e.g. strain 134, either contained less, or a different form, of this antigen than others, and that a single injection of vaccine into mice produced very little bactericidal antibody. Antibody was produced in rabbits by a single injection and in mice after more than four doses. Strain 364 , the classical phase IV of Leslie \& Gardner (I93I), also failed to elicit bactericidal antibody consistently. The production in rabbits of bactericidal antibody active against $B$. pertussis, by other Bordetella species, gave inconsistent results. It therefore seemed worthwhile to see whether the antigen was ubiquitous, and if so explore more fully the ubiquity of the antigen and whether its demonstration could be of any value in classification.

Possible qualitative variations in the antigen possessed by different strains of $B$. pertussis have also been investigated. Their existence is the more likely because Aprile \& Wardlaw (I973a) were able to demonstrate, by in vitro tests, six antigenic determinants on the isolated LPS of Bordetella and related species. By haemagglutination inhibition they

\footnotetext{
* Present address: Clinical Research Centre, Harrow HAI 3UJ, Middlesex.

$\uparrow$ Present address: London School of Hygiene and Tropical Medicine, London WCIE $7 \mathrm{HT}$.
} 
showed at least four determinants on the surface of B.pertussis, independent of the phase of the strain (Aprile \& Wardlaw, 1973b).

\section{METHODS}

Strains. Bordetella pertussis phase I cultures were stored lyophilized, and grown after reconstitution on Bordet-Gengou medium. Strain $18-323$, the mouse-virulent strain, was originally obtained from Dr P. L. Kendrick (Michigan) and maintained at Elstree by mouse brain passage and lyophilization; strain 134 was from Dr H. Piersma (Lederle Laboratories), and strains 3865 and 3747 were obtained from Dr E. K. Andersen (Copenhagen) and are now available as NCTCr 0906 and NCTC 19808 from the National Collection of Type Cultures, Central Public Health Laboratories, London NW9 5HT. Strains D734, D6229 and D3I48 were isolated in 1967 in Bradford, Manchester and Dundee, respectively, during the Public Health Laboratory Service investigation of whooping cough. Strains L84 and w2275 were similarly received during the Medical Research Council's investigations, and were from Leeds and Cardiff in 1950 and 1953 , respectively. These strains represent a cross-section of isolates from three countries from 1930 to 1967 and are of a variety of serotypes.

All other organisms were grown on nutrient agar. Bordetella bronchiseptica strain 22-067 was obtained from Dr G. Eldering (NCTCI0540); other B. bronchiseptica strains were NCTC 8760 and NCTC8762. Bordetella parapertussis strains were NCTC 8250 and $\mathrm{C} 803$ from the Elstree Collection. Phase IV strains of B. pertussis were 364 (NCTCIO9OI) and L84 (NCTCI0902), derived at Elstree (from the phase I L84 strain described above) by repeated subculture on media of decreasing complexity until growing well on nutrient agar, and CN2217 similarly derived from strain I8-323 at Burroughs Wellcome.

Salmonella typhi strains were T4904 and T550I, and Brucella melitensis was strain GI54E (originally thought to be a phase IV B. pertussis strain, but investigated by Aprile (1972) as NCTC863I and subsequently identified as Brucella melitensis).

Vaccines. Bacterial vaccines were made from $\mathrm{I} 8 \mathrm{~h}$ cultures grown at $36^{\circ} \mathrm{C}$ on the appropriate solid media and harvested into saline. They were adjusted to the international opacity standard of 10 units and diluted to contain $10^{10}$ organisms $/ \mathrm{ml}$ for all vaccines except Salmonella typhi which contained $10^{9}$ organisms $/ \mathrm{ml}$. For routine use, they were heated at $56{ }^{\circ} \mathrm{C}$, the typhoid vaccine for $60 \mathrm{~min}$, the others for $30 \mathrm{~min}$. Vaccine held in a boiling water bath for $2 \mathrm{~h}$ was called 'boiled', and at $\mathrm{I} 5 \mathrm{lb} / \mathrm{in}^{2}$ for $30 \mathrm{~min}$ 'autoclaved'.

Isolated antigens. Lipopolysaccharides (LPS) from Bordetella species coupled to Shigella conjugated protein were prepared by Dr A. P. Maclennan (Maclennan, I960); LPS from strain L84 phases I and IV (sent to us by Dr L. Szabo), Escherichia coli conjugated protein and $B$. pertussis endotoxin were all as described previously (Ackers \& Dolby, 1972).

Antiserum preparations. Rabbits were injected intravenously and mice intraperitoneally. Suspensions of whole organisms were given to rabbits as increasing doses, 2 to 3 times a week for the smaller initial ones of $\mathrm{I} \times 10^{9}$ to $5 \times 10^{9}$ bacteria, decreasing to one dose a week for the larger doses of ${ }^{10^{10}}$ organisms. Mice were injected once weekly with a dose of $1 \times 10^{9}$ to $3 \times 10^{9}$ bacteria. LPS was given similarly to rabbits in increasing doses of to to $50 \mu \mathrm{g}$. All animals were bled $\mathrm{I} 4$ days after the last injection and the separated serum heated at $50{ }^{\circ} \mathrm{C}$ for $30 \mathrm{~min}$.

Bactericidal antibody titres. These were determined as described previously (Ackers \& Dolby, 1972) using a range of antiserum dilutions, guinea-pig serum as the complement source, and the serum-sensitive strain $18-323$ phase $\mathrm{I}$ as indicator.

Assay for adjuvant activity. Haemolysin production was used as described previously (Ackers \& Dolby, 1972). 
Table 1.The production of bactericidal antibody for Bordetella pertussis strain 18-323, rabbit antisera after eight to ten injections of suspensions of heat-killed whole organisms

The injections were routinely given intravenously with an occasional intraperitoneal injection. Suspensions contained $10^{10}$ organisms $/ \mathrm{ml}$, and doses were from 0.2 to $\mathrm{I} \cdot 0 \mathrm{ml}$.

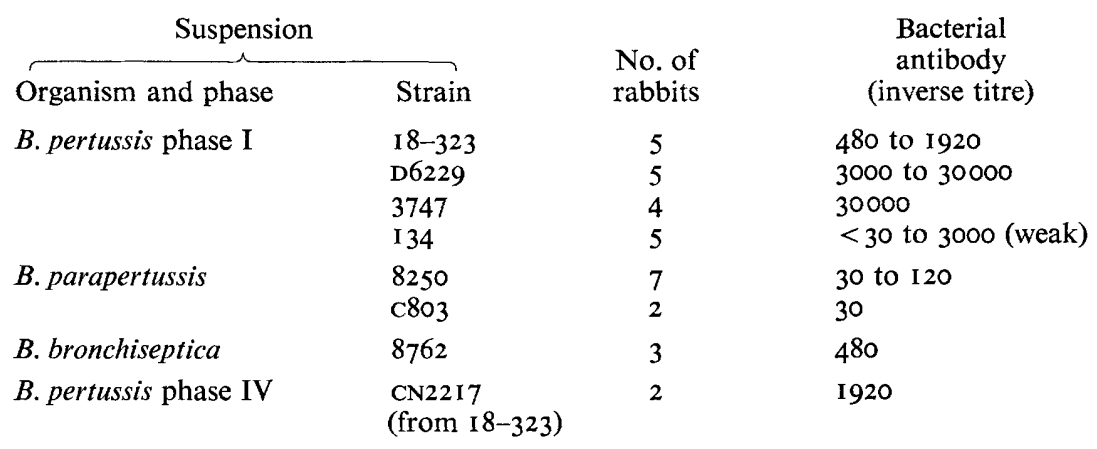

RESULTS AND DISCUSSION

A comparison of the bactericidal antibody response in rabbits and mice to Bordetella pertussis and other species

Most strains of Bordetella pertussis phases I and IV consistently elicited reasonable titres of bactericidal antibody when injected into rabbits (Table I). Strain I34, however, produced variable titres; the sera of three of five injected rabbits were not bactericidal at the highest concentration tested, the other two were weakly active at dilutions of $r / 2000$ to $r / 3000$. Two strains of $B$. parapertussis and one of B. bronchiseptica (Table I) produced very low titres, confirming the earlier results of Dolby (I965) that these may be lower than those of some 'normal' (uninjected) rabbits; the high titres sometimes found in previously uninjected rabbits are therefore probably not due to natural $B$. bronchiseptica.

LPS, the 'bactericidal antigen' from the three Bordetella species pertussis, bronchiseptica and parapertussis, coupled to Shigella conjugated protein were next injected into rabbits with no demonstrable antibody titres before injection. The resulting $B$. pertussis antisera were far more active than the other two, with titres of about $1 / 7680$, whereas the maximum for $B$. parapertussis strain 8250 was $\mathrm{I} / \mathrm{I} 20$, and there was no activity at $\mathrm{I} / 30$ with antisera to B. bronchispetica strain 8760 .

These results suggested that careful selection of rabbits would be necessary to identify Bordetella pertussis independently of phase. Mice had previously been found to produce antibody only weakly or not at all to some strains, e.g. I34, unless vaccination was more extensive than in rabbits, in which antibody was often elicited more easily, if inconsistently. However, mouse sera from all unvaccinated animals had no demonstrable bactericidal activity (Pusztai, Csizer \& Joo, 1971 $a$ ).

The number of injections required to produce antibody to a variety of strains was determined from the comparative antibody titres in pooled sera from groups of five mice. All strains of $B$. pertussis tested, including those which stimulated antibody production poorly or not at all after one dose, produced high titre antisera after 7 doses (Table 2).

Three doses of strains D3I48 and w2273 produced titres as high as three doses of strain L84 phase IV, but three doses of strain 364 elicited antisera which were only weakly active at $\mathrm{I} / 30$. Strain $\mathrm{I} 34$ did not elicit bactericidal antibody in mice after 4 doses (Ackers \& Dolby, I972). 
Table 2. The production of bactericidal antibody by mice; antisera to suspensions of whole organisms following one and seven doses of various heat-killed strains of Bordetella pertussis

Injections were given intraperitoneally in 0.1 to $0.5 \mathrm{ml}$ doses. One injection of $2 \times 10^{9}$, or seven injections of $1 \times 10^{9}$ to $3 \times 10^{9}$ organisms were given.

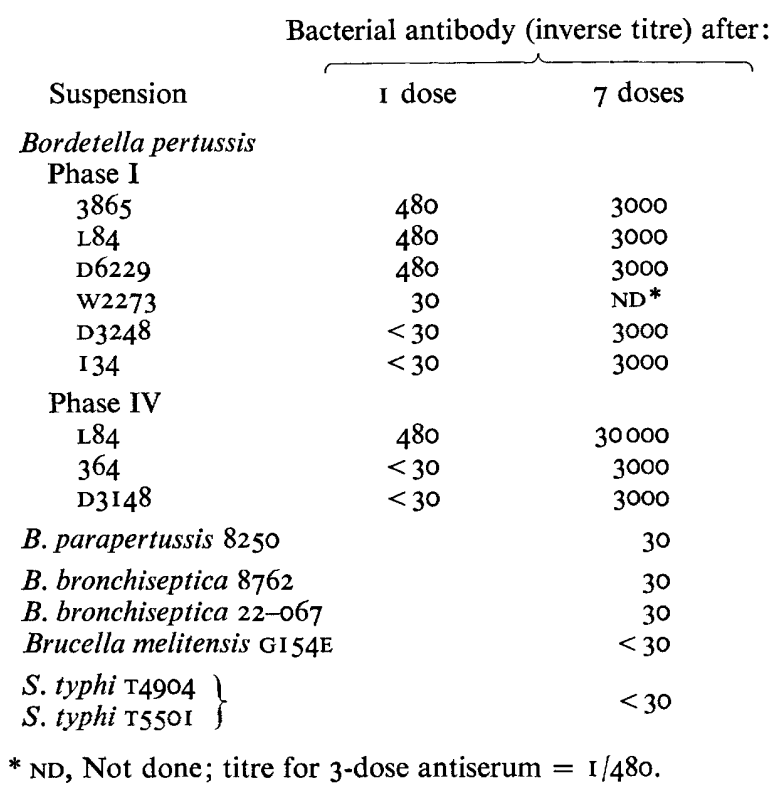

The bactericidal antibody titres of $\mathrm{I} / 3000$ or more after 7 injections into mice was specific for B. pertussis. Bordetella parapertussis strain 8250 and $B$. bronchiseptica strains 7862 and 22-067 gave titres of only I/30. Two unrelated organisms, Brucella melitensis and Salmonella typhi, have been similarly tested and antibody was not detectable at $1 / 30$. It would seem therefore that measurement of bactericidal antibody titre in the sera of mice vaccinated 7 times could distinguish otherwise unidentifiable strains of B. pertussis.

\section{Effect of boiling and autoclaving on the ability of whole organisms to elicit bactericidal antibody}

Subjecting B. pertussis vaccines to $100{ }^{\circ} \mathrm{C}$ or more impaired the antigenicity of 'bactericidal antigen', in spite of the fact that antibody formation depended on heat-resistant LPS (Ackers \& Dolby, 1972). Vaccines heated at $56^{\circ} \mathrm{C}$ for $30 \mathrm{~min}$ (the routine treatment) elicited a bactericidal antibody response equal to that of formol-killed or living organisms. Boiling the vaccine for $2 \mathrm{~h}$ decreased the antibody response in mice following one injection, although antibody was present after 4 injections, for strains D734 and phase I L84 (Table 3). Results for autoclaved vaccines are few, but this treatment probably impaired the antigen even further (L84 phase I and CN22 I 7 phase IV, Table 3). Phase IV strains may have more heat labile 'bactericidal antigen' than phase $I$.

The bactericidal antibody eliciting capacity of strains initially low in bactericidal antigen (Table 3), was abolished for 4-dose rabbit antisera by boiling (W2273) and for 8-dose rabbit antisera by autoclaving (364). Vaccination courses were not prolonged further to determine 
Table 3. The effect of boiling and autoclaving vaccines of B. pertussis on their ability to elicit bactericidal antibody

Vaccines were exposed to $56{ }^{\circ} \mathrm{C}$ for $30 \mathrm{~min}$ (heated), or $100{ }^{\circ} \mathrm{C}$ for $2 \mathrm{~h}$ (boiled) or autoclaved at $15 \mathrm{lb} / \mathrm{in}^{2}\left(\mathrm{I} 20^{\circ} \mathrm{C}\right.$ ) for $30 \mathrm{~min}$. The sera were raised in mice (given intraperitoneal vaccine) with the exception of those results followed by $(R)$ for which rabbits (vaccinated intravenously) were used. Since rabbits produced antibody more easily and the significant rabbit antiserum titres were all low, it has been considered valid to use these results. Antibody titres were determined in fourfold dilutions and expressed as the final dilution (inverse titre).

Vaccine made from

$\begin{array}{lc}\text { Strain } & \text { Phase } \\ \text { L84 } & \text { I } \\ \text { L84 } & \text { IV } \\ \text { D734 } & \text { I } \\ \text { W2273 } & \text { I } \\ \text { CN2217 } & \text { IV } \\ \text { 364 } & \text { IV }\end{array}$

\begin{tabular}{|c|c|}
\hline \multicolumn{2}{|c|}{ Heated } \\
\hline I-dese & 4-dose \\
\hline 120 & 7690 \\
\hline 480 & 30720 \\
\hline 480 & 30720 \\
\hline$<30$ & 480 \\
\hline ND & $<$ I920(R) \\
\hline$<30$ & 480 \\
\hline
\end{tabular}

ND, Not done.

$\begin{array}{cc}\overbrace{\text { I-dose }} & \text { 4-dose } \\ 30 & \text { I920 } \\ <30 & \text { ND } \\ <30 & \text { 1920 } \\ \text { ND } & 30(R) \\ \text { ND } & \text { ND } \\ \text { ND } & \text { ND } \\ \text { * 8-dose. } & \end{array}$

Autoclaved
4 -dose
480
$<30$
ND
ND
I $20(\mathrm{R})^{*}$
$<30(\mathrm{R})^{*}$

if the 'bactericidal antigen' had been completely destroyed. Whether this complete destruction occurred merely because there is less antigen initially in these strains cannot be determined from these results.

The I- and 4-dose mouse antibody titres produced by boiled suspensions of L84 phase I and D734 (Table 3) are very similar to those produced by unboiled suspensions of the low 'bactericidal antigen' strains W2273, D3248 and I34 (Table 2). We therefore wondered if the low 'bactericidal antigen' strains had a small amount of the antigen, or whether there were two 'bactericidal antigens' - one, a good antigen producing high antibody titres after a single dose, but labile to heat, the other heat stable but only producing measurable titres after several doses (the normal strains would possess both antigens, but the 'low antigen' strain only the second). To distinguish between the two hypotheses we attempted bactericidal antibody assays on antiserum to D734 absorbed with boiled homologous suspensions. The absorbed sera were negative for bactericidal antibody even after one absorption, suggesting that boiled suspension could remove all the antibody. The absorbed sera were either anticomplementary, or contained soluble antigen from the absorption which converted the serum-sensitive indicator strain into an insensitive one, as does LPS adsorbed on to the bacterial surface (J. M. Dolby, unpublished). The results were thus invalid.

We suggested above that the difference between strains eliciting bactericidal antibody early and those which do so only after several injections may be due to the presence of two antigens, one destroyed by heat; this is perhaps made more plausible by the existence of a similar situation in adjuvant activity. Isolated B. pertussis LPS is a heat-stable adjuvant, but the adjuvancy of whole-organism vaccine is much greater than can be accounted for by the content of LPS, and a potent, heat-labile adjuvant has been described (Pieroni \& Levine, I966). The postulated labile 'bactericidal antigen' cannot be identical with the labile adjuvant, because whole-organism vaccines of strain I34 (producing bactericidal antibody only after repeated injection) and strains D6229 and L84 phase I (producing antibody after single doses) have indistinguishable activities as adjuvants (Ackers \& Dolby, 1972). 


\section{Investigations on 'bacterial antigen'}

Isolated LPS does not elicit bactericidal antibody unless it is coupled to a carrier, for example, a bacterial conjugated protein (Partridge \& Morgan, 1940). Endotoxins prepared by extraction with cold trichloroacetic acid are antigenic without further treatment. Such preparations either did not elicit antibody after one injection or did so only very poorly, i.e. they resembled boiled vaccines of whole organisms. Assays of 4-dose mouse antisera showed that the antibody-eliciting capacity of isolated LPS from L84 phase I or endotoxin from D6229 was not further affected by boiling. Since they already resembled boiled vaccines in their inability to elicit antibody after one injection, this was perhaps not surprising, but it prevented us from determining, on extracted material, the site of the lability, LPS or carrier, or investigating the possibility of two types of LPS. Perhaps the decreased activity of extracted LPS in itself suggests that the effect is on the LPS. One attempt to make 'bactericidal antigen' with homologous conjugated protein failed.

Although the adjuvanting property of endotoxin is not dependent on the same group in the LPS molecule as 'bactericidal antigen' (Ackers \& Dolby, 1972), antisera to red cells adjuvanted with extracted LPS from L84 phase IV were also of lower titre than those adjuvanted with whole bacteria. Boiling the LPS for 30 min did not decrease the adjuvancy further.

The authors thank Miss Claire Hilton and Mr David Simpson for haemolysin and bactericidal antibody titrations, respectively. They are grateful to Dr A. P. MacLennan and Dr L. Szabo for samples of bacterial lipopolysaccharide.

\section{REFERENCES}

ACKers, J. P. \& Dolby, J. M. (1972). The antigen of Bordetella pertussis that induces bactericidal antibody and its relationship to protection of mice. Journal of General Microbiology 7o, 371-382.

Aprile, M. A. (1972). A re-examination of phase IV Bordetella pertussis. Canadian Journal of Microbiology I8, I793-I80I.

Aprile, M. A. \& WARdlaw, A. C. (I973a). Immunochemical studies on the lipopolysaccharides of Bordetella pertussis. Canadian Journal of Microbiology 19, 23 I-239.

Aprile, M. A. \& Wardlaw, A. C. (I973 $b$ ). Availability and specificity of lipopolysaccharides on the surface of $56^{\circ} \mathrm{C}$ heated Bordetella pertussis. Canadian Journal of Microbiology 19, 536-538.

Dolby, J. M. (1965). The antibacterial effect of Bordetella pertussis antisera. Immunology 8, 484-498.

Leslie, P. H. \& GARDNER, A. D. (I93I). The phases of Haemophilus pertussis. Journal of Hygiene 31, 423434 .

Maclennan, A. P. (1960). Specific lipopolysaccharides of Bordetella. Biochemical Journal 74, 398-409.

PARTRIdGe, S. M. \& Morgan, W. T. J. (I940). Immunization experiments with artificial complexes formed from substances isolated from the antigen of Bact. shigae. British Journal of Experimental Pathology 21, I 80-195.

Pieroni, R. E. \& Levine, L. (I966). Adjuvant principle of pertussis vaccine in the mouse. Nature, London 2II, I4I9-I420.

Pusztai, Z., Csizer, Z. \& Joo, I. (I97I $a$ ). The effect of different bactericidal systems on B. pertussis and B. parapertussis organisms. Zeitschrift für Immunitätsforschung und experimentelle Therapie I4I, I-I3.

Pusztai, Z., Csizer, Z. \& Joo, I. (I97I $b$ ). The role and specificity of Bordetella lipopolysaccharide in immune reactions. Zeitschrift für Immunitätsforschung und experimentelle Therapie I4I, I29-I40. 